\title{
ONLINE IDENTITY IN A PANDEMIC - FROM INNOVATION \\ PRACTICE TO COMPETITVE ADVANTAGE THROUGH THE LEARNING PROCESS
}

\author{
Michaela Mihaylova ${ }^{1}$
}

DOI: https://doi.org/10.31410/LIMEN.2020.91

\begin{abstract}
The current chapter presents the transformation of perception about the online identity of a business in the context of the COVID-19 pandemic. Online identity and related marketing activities, perceived until only recently as innovative actions, today are a prerequisite for a competitive advantage. The chapter comments on the general knowledge and understanding of this topic, the different types of innovations, the elements of online identity and the marketing actions related to them. The competitive advantage and the evolved view of its nature are outlined as a positive transformation - a creation of new knowledge as a result of the learning processes application.
\end{abstract}

Keywords: Online identity, Competitive advantage, Innovation, Learning, Pandemic.

\section{INTRODUCTION}

$\mathrm{T}$ The phrase "we live in dynamic times" has never had as big of meaning as in 2020 . The conditions of the pandemic have led to a change in every aspect of consumer and business habits. Physical communication not only became secondary ad interim but is also considered a condition for danger, synonymous with risk and irresponsibility in both personal and business contexts. The abbreviation 3 "D" - disinfection, discipline and distance, is becoming one of the most common and recognizable worldwide. Both companies and consumers have been faced with a huge challenge in terms of the limits of their adaptability. The already established practices and relationships had to be maintained, but the question was, how? With physical contact kept to a minimum, the communication environment shifted solely to the Internet. This allowed the companies with a substantial online presence to evolve from innovators to architects of one of their most important sustainable competitive advantages.

This article aims to outline the increasingly important role of online identity and the realization of a business that operates in a pandemic, as these are businesses that are considered responsible and adaptive nowadays - they offer their users the opportunity to exchange information in a way relevant to the situation.

\section{THE FUNDAMENTALS OF ONLINE IDENTITY AND ITS DIMENSIONS}

The fact that the Internet is a tool for commercialization has been long documented. "In 2019, the number of internet users worldwide stood at 4.13 billion, which means that more than half of the global population is currently connected to the Internet" (https://www.statista.com). Choosing a channel for communication on the Internet is a complex task as defining the goals behind it. Online marketing is undergoing many transformations in the online environment. Perceived and applied initially as a traditional approach - as a means of selling products and

$1 \quad$ VUZF University, Gusla 1 str., 1618 Sofia, Bulgaria 
services - today one area of online marketing is attracting more and more attention - Inbound Marketing. The motive behind the transformation of online marketing is the evolution of consumer perceptions, the change in their habits, and the growing role of interaction processes in terms of building and perceiving corporate images. As a consequence of this change - a "digital customer" concept has been presented where the "Internet consumer" is defined as "physical person or an institute who or that intends to purchase, purchases or has already purchased goods or services (including through the third parties) with the help of informational-telecommunication technologies." (Krasnov, Chargaziya, Griffith \& Draganov, 2019).

Currently, consumers need security. And not the security that has been synonymous with trust and confidence so far, but rather security in a pandemic. The current challenge that lies in front of the business is to provide this type of security without losing market share and presence, while at the same time making sure that the consumers are not changing their habits and are remaining loyal to the companies they have been with so far. In the COVID-19 pandemic, one of the important conditions for compliance is physical distance. And the Internet is certainly a way to provide distance. In a way, the current situation provides a paradox - created to diminish the distance between people, today the Internet is a way to ensure it. Marketing activities occur through three types of channels: distribution, transaction, and communication. The Internet is used as a transaction channel to generate sales. The second channel is distribution, allowing exchange between goods and services, and the third one, which is especially important today, is the communication channel. Communication is the basis of the partnership between the consumers and the company. It is a process generating extremely valuable information about the business. Communication is a confirmation of the importance of socializing. From the users' point of view - communication is not only a way of expressing an opinion but also a way of receiving information and updates. For companies, communication is a way to build a presence, to provoke a reaction as a prerequisite for gathering information about the market.

We previously mentioned Digital Inbound Marketing, which "represents the process of reaching and converting qualified consumers by creating and pursuing organic tactics in online settings" (Opreana \& Vinerean, 2015, p. 30). In addition to the definition, Opreana and Vinerean comment on the main manifestations of Inbound Digital Marketing - Search Engine Optimization marketing, Email marketing, Blog marketing, Content Marketing, Social Media marketing. This part of online marketing allows you to build long-term relationships with customers. This is feasible through the technical capabilities provided by the Internet when registering user actions (number of clicks, duration of time spent on a website, number of written comments). Based on this set of information, the company has up-to-date information for consumers and prospects.

But in order to receive this information - the company must invest in several main areas:

- website development,

- creating and maintaining pages on social networks,

- creating backlinks,

- the use of email marketing platforms.

Website development refers to building a website. Building a website includes decisions related to creating a single plain-text webpage or developing a complex web application. Taking into consideration the fact that every business is different, we could confirm that the positive effect of having a website may differ according to business specifics. One of the main benefits that a website as an online element brings is the establishment of credibility for the 
business. Other positive consequences of website creation are accessibility 24/7, building connection with customer, resource of company information, an increase of company's visibility, confirmation of company responsible approach in pandemic satiation. Backlinks are important for a website in order to receive consumers directly from search engines like Google or Bing. A backlink represents the connection between your website and another one. When a search engine recognizes your website links to another, it is considered that your website is more worthy of appearing within your search results. The result is - the more backlinks - the higher ranking in search engines. There are many possibilities to build a backlink but this process has a lot of peculiarities that have to be taken into consideration. For example - the websites which "backlink" yours should be carefully selected because the connection with another site reflects on the reputation of yours. The power of social networks is related opportunity to "humanize" your brand or to close the distance (of course in a pandemic context - this is not the best expression) between your company and your brand. The social media presence is related to the company's website because it could contribute to increased website traffic. In the COVID-19 situation, social media are the best example of an element of online identity for crisis communication. Customer engagement or monitoring the competitors are other characteristics of company pages on social networks. The Internet offers the possibility to track customers' actions in real-time. Thus, e-mail marketing can be tailored to them. This online identity element assures relevant communication with customers according to their interests due to the trackability characteristic of the Internet. In order to achieve a high level of customer engagement, the communication via e-mail could refer to changes in the company or request feedback from the customers. E-mail marketing should be a balanced approach applied regularly and moderately. Similarly, in every other element of the online environment, results from e-mail marketing campaigns could be measured. Besides, one of their specifics is that they are action-oriented and could also contribute to website traffic. The investment in online marketing and its related activities is characterized by long-term results. Strategies related to building an online identity do not yield quick results. They are based on the concepts of relationship marketing. Figure 1 - Relationship marketing stages illustrates the stages that this process usually goes through:

Figure 1. Relationship marketing stages

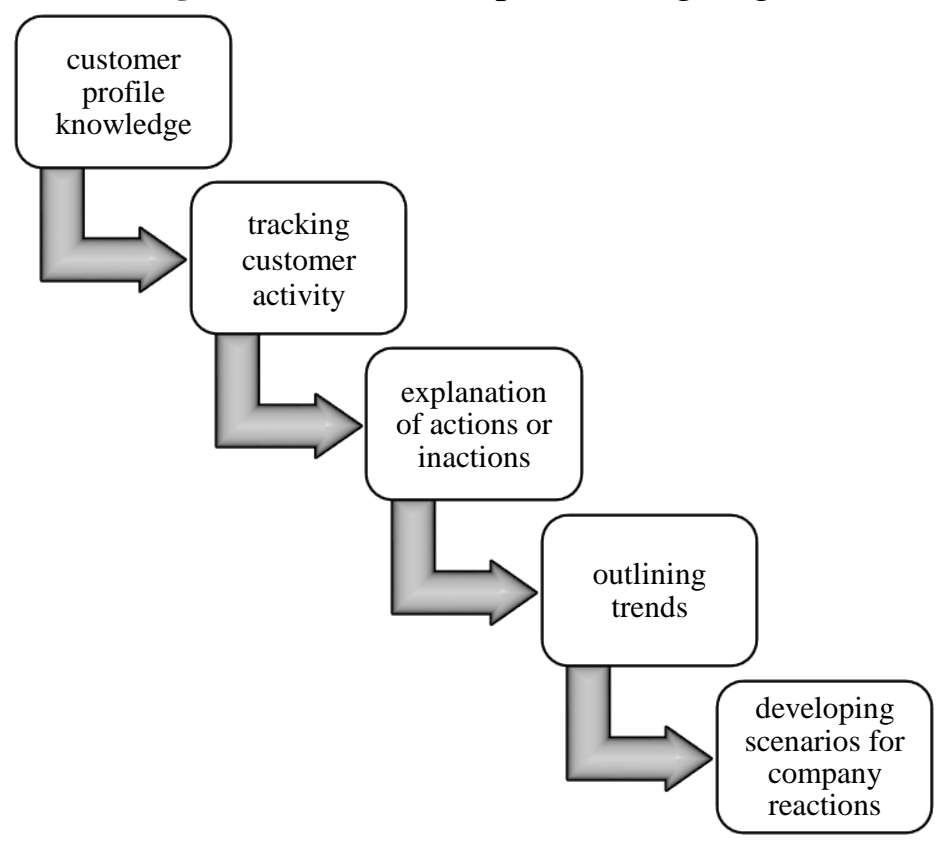

Source: Authors processing 
The long period required to generate and produce results is offset by their sustainability. By developing and maintaining a good and SEO optimized website, rhythmically copywriting for the purposes of backlink strategies, maintaining pages on social networks filled with interesting and useful content, as well as keeping in touch with prospects and clients through e-mail marketing, companies will build a sustainable Internet presence. This presence will provide an opportunity to communicate with consumers from a distance, to contribute to building relationships, to strengthen their market presence and to an overall sense of increased social responsibility. If until recently everyone repeated the mantra that the future is happening on the Internet, today we realize how important it is to adapt quickly - because being dynamic is a key feature of our time. And if online identity before the pandemic was a complementary activity, today it is associated with sustainability, longevity and flexibility, and adaptability. In addition, it ensures that a competitive position is maintained and sometimes even a competitive advantage is created.

\section{ONLINE IDENTITY IN THE CONTEXT OF INNOVATION}

When physical communication was still considered a form of common and typical communication, despite the growing role of the Internet in everyday life, not all companies were aware of the potential and high levels of adaptability it offers. Building an online identity was even considered innovative. Below we will look at the different interpretations of innovation, grouped according to different criteria.

There are different classifications when it comes to grouping and differentiating innovations. First of all, they can be distinguished according to the level at which they manifest. If the innovation takes expression inside the company, then it is internal. If the innovation is related to the external manifestations of the company's actions - then it could be qualified as external.

Internal innovations affect administrative processes, company structure, technologies and methods used, and external innovations are expressed through products and services. Even in the recent past, the main notion of innovation has been limited to its outward manifestation. But time has proved this is a limitation, and Han, Kim and Srivastava (1998) are one of the scientists who share their expanded perception of innovation as a process that is not just tied to a new product. Therefore, today there is more and more talk about the importance and contribution of innovation in its expression as a new process or new organizational structure.

Innovation literally means modernization or transformation, and the general perception of it could be expressed as the transformation of scientific knowledge into a marketable product. The transformation of knowledge into innovation is a process based on a certain set of abilities (Ozkaya, Droge, Hult, Calantone \& Ozkaya, 2015) or 'skills', as Li and Calantone (1998) call them. These skills are organized into four groups, depending on whether they take place outside or inside the company. The first two skills concern the knowledge of competitors and consumers. They, as representatives of the external environment for the company, influence and outline to a certain extent its decisions, plans, and approaches. The third and fourth skills are related to coordination, in particular that of marketing activities and research and development. Marketing activities vary depending on the goals of the companies but could be organized into a marketing program that combines goals, strategy, costs, results, and time required. So logically, online identity comes first in the skills associated with marketing activities. Interestingly, in addition to these skills, online identity can be a part of the skills of market awareness - knowing competitors and consumers. We can draw this conclusion from the fact that the online presence in a pandemic is in line with the limited ability of users to 
contact companies (along with their products and services), in addition to their evolving needs in terms of technology and interactive communication. Online presence is a skill for competitiveness because in its presence it becomes a reference point and, in its absence - it makes the company a pioneer in this activity. Innovation is divided into two types administrative and technological (Damanpour, 1991) ${ }^{2}$. The administrative refers to the processes related to the administration, and the technological to the products and services that the company offers and develops. So logically, one can find the similarity between administrative and internal innovation, as well as between technological and external innovation. Schumpeter is an Austrian economist who believes that innovation is at the heart of generating profit. According to him, innovation is "a process of industrial mutation, which incessantly revolutionizes the economic structure from within, incessantly destroying the old one, incessantly creating a new one" (Schumpeter, 1942). Schumpeter (1934) offers organizing innovations in 5 groups, almost 100 years ago:

(a) the placing on the market of a new product or new varieties of an already known product;

(b) the application of new production methods or those affecting sales;

(c) conquering new markets;

(d) use of new sources for the supply of unprocessed or semi-processed raw materials;

(e) restructuring of sectors, for example establishment or destruction of a monopoly position.

Of course, these notions are based on production specifics in that period. Through a distant reference, online identity, along with all related marketing activities, can be classified as the first type of innovation. It is the new kind of offering products and services, the new form of regular communication, and the new way of expressing and reflecting user feedback. By analyzing Schumpeter's understanding, we can conclude that stagnation is the antithesis of innovation. Innovation is associated with dynamics, with the ability to accept change and adapt to it. And despite the various manifestations of innovation, it always moves companies forward, shows recognition of the new, and a desire to apply and develop an adapted and structured approach to it.

\section{IMPLEMENTING INNOVATIONS THROUGH ORGANIZATION LEARNING}

Innovation is possible when it corresponds to the internal and external environment. In the context of external environment conditions - the innovation should be developed if micro-and macroenvironment factors are taken into consideration. Macroenvironment factors such as demographic, economic, political, cultural ones play a framing role during the whole innovation development cycle, because the company does not function in isolation. For example, GDPR significantly changed the regulation related to data collection and usage on the Internet. Consumers, competitors, distributors and suppliers are representatives of microenvironment. Consumers are one of the main generators of innovation ideas because every company develops its products and services in order to meet and answer to their needs and expectations. Competitors as external actors of the microenvironment should be monitored and analyzed. As a consequence of this analysis, the company could protect its market share and adapt its actions and plan according to the current competitive situation.

The main and unique representative of the internal environment is the company itself. The company is a set of processes, organizational structure, employee skills, qualification level of different departments such as Marketing, Finance, Production as well as interdepartmental 
connections. All these dynamic and static elements are a source of information which should be taken into consideration when developing an innovation. In other words, the internal and the external environment along with their participants and peculiarities should be considered as an informative resource in the context of the innovation. The company should constantly analyze the information related to current and past moments because this practice contributes to the decision for an innovation development followed by its implementation to be successful. A premise or a consequence of this practice is the striving for constant learning. Support for the validity of this conclusion can be found in Crossan and Apaydin's (2010) statement that innovation is a multidimensional construct, which includes different determinants (as resources designated the particular innovation, company structure and strategies, corporative structure) and one of them is the organizational learning. Sinkula (1994) differentiates three stages within the multidimensional construct of organizational learning: information acquisition, information diffusion and information sharing. In the current chapter, we share an expanded understanding of this process by adding the "undertaking of relevant actions" as a fourth stage. Organizational learning is a constant process, which beginning and end could be difficultly outlined. It resembles even circular economics (topic commented and analyzed in many papers by V.Zhelyazkova, 2019) because the main idea of circular economics proclaims that in nature nothing is lost, nothing is created, everything changes (Antoine Lavoisier) and that the end of an activity is the beginning of a new one. Analogically, when commenting on organizational learning - the stage of the undertaking of relevant actions is being preceded by the one of information acquisition - but only at first sight - because it could be its predecessor since undertaken actions provoke acquisition of information related to their reverberation around the external and internal environment. Knowledge could be divided to component and architectural (Tallman, Jenkins, Henry \& Pinch, 2004). The component type represents the recognizable part of the organizational structure - e.g. academic and technical engineering skills, or skills that apply to analyzing customer behavior, sales planning and execution and marketing-driven actions. Component knowledge can "leak out" from the organization because it is a constantly circulating set of skills and information. Architectural knowledge - is intangible. It is complex and could be described as a fund of knowledge. Its creation is a result of the individual and unique experience developed within the company. This type of knowledge is the foundation of a successful competitive advantage. Absorptive capacity (ACAP) or a firm's ability to acquire, assimilate, transform, and apply knowledge. This ability is being developed upon:

- Technology knowledge;

- Customer knowledge;

- Competitors knowledge.

Technology knowledge has a direct contribution to the development and application of innovations. Customer knowledge adds value for the users through the specific innovation. When we come to the competitors one could assure superiority or could generate a relevant reaction to competitive actions. The current chapter already confirmed the relation between innovation and dynamics and the one between innovation and the ability to handle and to properly react to a change. In addition, Zahra and George (2002) describe the ability to assimilate organizational learning as a dynamic one aiming at reaching a sustainable competitive advantage.

As a consequence, the learning process and the knowledge acquisition could be defined as a driving force for the company to adapt within the market's conditions, also innovation could be one of the results and manifestations of this process. 


\section{ONLINE IDENTITY AS A SUSTAINABLE COMPETITIVE ADVANTAGE}

Innovation based on market knowledge creates a new type of value and this is a premise of sustainable competitive advantage (Zhou, Yim \& Tse, 2005). The sustainable competitive advantage is commonly related to customer's intention to choose a given product or service due to the perception for the higher quality received. Competitive advantage is ,something that the firm does better than its competitors, that give it an edge in serving customers' needs and/or maintaining mutually satisfying relationships with important stakeholders "(Ferrell, 2012, p.16).

We would achieve the transition to sustainable competitive advantage analysis by specifying that organizational learning in its adaptive aspect aims at satisfying needs that already exist when the goal of generative learning is to predict customer's needs. In pandemic context it is requirable to comment on Maslow's hierarchy of needs and more concretely why its second level (safety /shelter, security, both physical and financial) should be a point of reference. Any product or service needs to focus on the establishment of customer safety and not to jeopardize their health, and this is most easily accomplished in the online environment. Thus, we could confirm that every company, which has a well-developed online presence, has been applying the generative approach (according to organizational knowledge classification). Such companies have succeeded in foreseeing customer needs, and competitive advantage has been created as a consequence. In other words, maintaining competitive advantage represents a system of activities related to analysis and anticipation of internal and external factors and the effects that they could potentially generate. And when competitors' monitoring is being added to these activities, then the competitive advantage grows in a sustainable one. Nakova (2007) defines the criteria in order for the sustainable competitive advantage to be significant for a company. Several of them are:

- The level its influence on market share,

- The level its influence on the company's profit,

- The level of its "ability" to provoke/prevent a company's instability,

- The level of its importance for the company's reputation.

We would like to add that the most significant criteria for sustainability of an advantage in online environment is its geographical independence. The online identity depends only on the company's resources and decisions and it does not depend on the geographical peculiarities of the regions where customers are located. According to Day (1994) the potential to develop a competitive advantage as a set of skills and abilities. They represent the bonding mechanism between all the available resources, knowledge and skills within an organization and they contribute to company's activities execution.

- Sources of advantage. This group of advantages is based on superiority skills and resources.

- Positional advantages. Advantages based on a higher customer value and on lower expenses.

- Company results. Market share, customer satisfaction, loyalty, profit.

When commenting the online presence and identity - every company should designate a budget dedicated to these activities. If such financial resources were provided in the past - today they are transformed in superior ones. And if we differentiate two types of businesses: online based and such based on both markets (the online and physical), we can claim that the right resource balance between online and offline activities results in intentionally pursued competitive advantage. 
In the online context, the important superiority competencies are related to:

- understanding business in online environment,

- ability to adapt,

- knowledge and positive attitude toward new technologies' application,

- analysis of information generated in online environment.

Logically, the perception for sustainable competitive advantage evolves. This comes as a result of the necessity for confirmation of its characteristics in the dynamic conditions of a different time context. According to Fiol (Fiol, 2001) achieving sustainable competitive advantage is possible when it is based on specific internal skills and competencies and it does not depend on the level of its imitability. These internal competencies are discussed by other authors ${ }^{21}$ in the last 40 years. They are being perceived as a set of available resources, competencies and skills within the company, as well as a way in which they are used and implemented in order to generate revenues. This long period again confirms the intransitive importance of competitive advantages when commenting the functioning of the business. It is Fiol (2001) again who claims that in the $21^{\text {st }}$ century the major factor for an advantage to be a competitive one is not a synonym of the inability for imitation. The superiority and sustainability originate from the ability and the power to deconstruct and restructure existing habits and resources. A foundation of creating, developing and managing a fixed set of valuables resources is a stable organization where values and a sense of belonging exist. In such an organization positive attitude toward changes is spread.

\section{CONCLUSION}

This pandemic influenced the trivial round of every customer and every business. During the searching process related to protection of market share some companies understood that their prevailing hither to investments in creating an online identity, resulted in the presence of competitive advantage. During this process companies implemented different adaptability implementation practices in order to keep the contact with their customers in compliance with the COVID-19 protection regulations. The rest of the companies became aware of the of the sustainability as an important characteristic of the online identity, especially in dynamic competitive environment.

This could be called a transformational one regarding the online activities' concept and more precisely - their conversion from innovational act to competitive advantage. The detailed comment of possible activities in online environment contributing to the creation of a company identity (e.g. Website or profiles in social networks) shows their complex nature and that they complement one another. The essence of these activities makes an allusion to organizational learning necessity as a binding element aiming their positive adoption and integration with the company's activities. Of course, the sustainable competitive advantage has the full meaning of sustainability when it is perceived as a dynamic element that is being developed in order to correspond to the dynamic environment where the companies operate.

\section{REFERENCES}

Crossan, M., \& Apaydin, M. (2009). A Multi-Dimensional Framework of Organizational Innovation: A Systematic Review of the Literature. Journal Of Management Studies, 47(6), 1154-1191. doi: 10.1111/j.1467-6486.2009.00880.x 
Damanpour, F. (1991). Organizational Innovation: A Meta-Analysis Of Effects Of Determinants and Moderators. Academy Of Management Journal, 34(3), 555-590. doi: $10.5465 / 256406$

Day, G. (1994). The Capabilities of Market-Driven Organizations. Journal Of Marketing, 58(4), 37-52. doi: 10.1177/002224299405800404

Day, G. S., and Wensley, R., (1988) Assessing Advantage: A Framework for Diagnosing Competitive Superiority. Journal of Marketing, 52(2), 1-20

Ferrell, O. C., Marketing Strategy: Text and Cases, Cengage Learning, 2012.

Fiol, C. (2001). Revisiting an identity-based view of sustainable competitive advantage. Journal of Management 27 (6), 691-699.

Han, J., Kim, N., \& Srivastava, R. (1998). Market Orientation and Organizational Performance: Is Innovation a Missing Link? Journal of Marketing, 62(4), 30-45. doi: $10.1177 / 002224299806200403$

https://www.statista.com/topics/1145/internet-usage-worldwide/

Krasnov, A., Chargaziya, G., Griffith, R., \& Draganov, M. (2019). Dynamic and static elements of a consumer's digital portrait and methods of their studying. IOP Conference Series: Materials Science and Engineering, 497, 012123. doi: 10.1088/1757899x/497/1/012123

Li, T., \& Calantone, R. (1998). The Impact of Market Knowledge Competence on New Product Advantage: Conceptualization and Empirical Examination. Journal Of Marketing, 62(4), 13-29. doi: 10.2307/1252284

Nakova, R. (2007). Ustoychivo konkurentno predimstvo. Upravlenie i ustoychivo razvitie, 18, (3-4)

Nelson, R. R., \& Winter, S. G. (1982). An evolutionary theory of economic change. Cambridge, MA: Harvard University Press

Ozkaya, H., Droge, C., Hult, G., Calantone, R., \& Ozkaya, E. (2015). Market orientation, knowledge competence, and innovation. International Journal Of Research In Marketing, 32(3), 309-318. doi: 10.1016/j.ijresmar.2014.10.004

Rakthin S. et al. (2016). Managing market intelligence: The comparative role of absorptive capacity and market orientation.69(12), 5569-5577

Reed, R., \& DeFillippi, R. J. (1990). Causal ambiguity, barriers to imitation, and sustainable competitive advantage. Academy of Management Review, 15, 88-102.

Schumpeter, J.A. 1934, The theory of economic development: an inquiry into profits, capital, credit, interest and the business cycle, Harvard Economic Studies, Vol. 46,

Schumpeter, J.A. 1942. Capitalism, Socialism and Democracy, 3rd edition, London: George Allen and Unwin, 1976

Sincula, J.M., (1994), Market information processing and organizational learning, Journal of Marketing 58, 35-45

Tallman, S., Jenkins, M., Henry, N., \& Pinch, S. (2004). Knowledge, Clusters, and Competitive Advantage. The Academy Of Management Review, 29(2), 258. doi: 10.2307/20159032

Zahra, S. A., \& George, G. (2002). Absorptive capacity: A review, reconceptualization, and extension. Academy of Management Review, 27, (2),185-203.doi: 10.2307/4134351

ZHelyazkova, V. (2019). Vaznikvane i razvitie na kontseptsiyata za kragovata ikonomika. Kragova ikonomika i ustoychivi finansi. Savremenni perspektivi. 6-22

Zhou, Kevin Zheng, Yim, Chi Kin, \& Tse, David K. (2005). "The effects of strategic orientations on technology-and market-based breakthrough innovations." Journal of Marketing, 69, 42-60. 